\title{
PSICOANÁLISIS Y JACQUES LACAN
}

\author{
PSYCHOANÁLYSIS AND JACQUES LACAN \\ Renzo Pita Z.'; Roberto Galván S.; Amparo Pérez S.; Ana Surichaqui L.; Nayrovi Vásquez C.; \\ José Rios A. \\ Universidad Nacional Mayor de San Marcos, Lima, Perú \\ (RECIBIDO 03/2/2012; ACEPTADO 15/6/2012)
}

\begin{abstract}
RESUMEN
Este trabajo pretende mostrar parte del estudio realizado por el Grupo de psicoanálisis lacaniano de San Marcos, el cual toma como eje el postulado de Lacan el inconsciente se estructura como un lenguaje. Buscamos aquí realizar una primera aproximación a los argumentos que hicieron posible semejante enunciado, así como mostrar las consecuencias que produjo en el psicoanálisis su puesta en práctica. Para ello se hace un recorrido que inicia con una pequeña explicación sobre el lugar que ocupa Jacques Lacan en el psicoanálisis, luego se lleva a cabo un desarrollo sobre la estructura de lenguaje que hay en el inconsciente, para lo cual se hace referencia a Ferdinand de Saussure y a Roman Jakobson. Ya al final se introducen algunos conceptos como otro e intersubjetividad con el fin de mostrar el modo de abordaje clínico que se deduce de los postulados de Lacan.
\end{abstract}

Palabras clave: Jacques Lacan, psicoanálisis, estructura, lenguaje, significante, intersubjetividad

\begin{abstract}
This paper aims to show part of the study by the Lacanian Psychoanalysis Group of San Marcos University, which takes as the central postulate of Lacan the unconscious is structured like language, we make a first approximation to the arguments that made possible such a statement, and show the consequences that occurred in psychoanalysis during its implementation. For this paper we made a brief explanation of the place of Jacques Lacan in psychoanalysis, then performs a development on the structure of language that is in the unconscious, to which reference is made to Ferdinand de Saussure and Roman Jakobson. Finally, we introduce some concepts as Other and Intersubjectivity in order to show the clinical approach way that follows the tenets of Lacan.
\end{abstract}

Keywords: Jacques Lacan, psychoanalysis, structure, language, significant, intersubjectivity

1 Licenciado en Psicología UNMSM, egresado de la escuela de la Nueva Escuela Lacaniana de Lima. E-mail: renzompz@ gmail.com 
Hemos escogido como título "Psicoanálisis y Jacques Lacan", la elección tiene como motivo intentar tomar la atención del lector desde el punto de comprensión del psicoanálisis en donde suponemos se encuentra. Punto en donde sospechamos que sería necesario para él la conjunción "y" para asociar el psicoanálisis con Jacques Lacan, en tanto podría ser asociado también a una postura kleiniana, junguiana, etc.

Pensamos, sin embargo, que entre la invención de Freud y lo desarrollado por Lacan no existe un cambio trascendente, es decir que en el nivel de los fundamentos y los principios los postulados del primero se encuentran conservados en los del segundo, pero modificados por lo que podríamos llamar una generalización, o sea, llevados a un terreno más extenso pero conservando su lógica esencial. Por lo tanto consideramos que no hay una separación real entre el psicoanálisis lacaniano y el freudiano, que el primero no es una reinvención más del segundo, sino una continuidad, y que cuando usamos la expresión psicoanálisis lacaniano se hace alusión a esa operación que hemos denominado generalización.

El grupo de estudios de psicoanálisis lacaniano de San Marcos tiene entre sus objetivos demostrar la veracidad de dicha operación, mostrar su alcance y su pertinencia actual. No obstante, estamos advertidos que una de las dificultades más conocidas del psicoanálisis es su transmisión, admitimos que en buena medida esto se debe a un lenguaje que se presenta a primera vista encriptado y que parece accesible solo a aquellos que son cercanos a alguna sociedad psicoanalítica ${ }^{2}$.

Pretendemos por ello disminuir algunas de estas brechas sin más herramientas que el estudio, la investigación y la discusión abierta de los textos fundamentales del psicoanálisis y de casos clínicos en el espacio de la universidad. Este artículo se inscribe en esa línea y busca ser un medio para facilitar la lectura del psicoanálisis. Al mismo tiempo pretende hacer un recorrido al estilo de una sinopsis de lo que se ha trabajado y se trabajará en el grupo de estudios, labor que se ha enmarcado en lo que se conoce como la primera y la segunda enseñanza de $\operatorname{Lacan}^{3}$. Por lo tanto, dicho artículo consistirá en una presentación, no solo del psicoanálisis, sino también de algo que podría tener el nombre de programa de estudio.

Un buen punto de partida para un estudio de psicoanálisis es el que nos ofrece la pregunta ¿qué es el psicoanálisis?, ¿qué hace que el psicoanálisis sea tal? Nuestra hipótesis es la misma que la de Jacques Lacan: el psicoanálisis es la cura por la palabra, pues no tiene sino un medium: la palabra del paciente ${ }^{4}$.

2 Esto es sin duda más evidente en el caso de Jacques Lacan, pues su escritura es -como señala Jacques-Alain Miller-aforística y esconde la articulación razonada de sus enunciados. Todo ello tiene sin duda un porqué que no es posible explicar en este trabajo, no obstante ofrecemos una pequeña ayuda que, para variar, es algo enigmática pero que si se reflexiona facilitará la lectura de los escritos de Lacan: lo que se transmite en el contenido de sus escritos es tan o menos importante que lo que se muestra en su forma.

3 Nos referimos a la organización que hiciera Jacques-Alain Miller de la obra de Lacan, en la cual ubica tres momentos en su enseñanza. El primero se caracteriza por tomar como fundamental a las leyes de la palabra, el segundo por tomar como eje central a las leyes del lenguaje, y el tercero por colocar a su noción de real como el pivote de la práctica psicoanalítica. Las dos primeras pueden ser consideradas como dos formas diferentes de abordar la tesis el inconsciente se estructura como un lenguaje.

4 Jacques Lacan, "Función y Campo de la palabra y el lenguaje en psicoanálisis", en Escritos 1, (Buenos Aires: Siglo XXI, 2008$), 240$. 
Esta proposición implica en primer lugar que, si bien es cierto, el medium es la palabra, el uso que hace de esta el psicoanálisis es lo que lo diferenciaría de otros procedimientos que también se valen de ella, como por ejemplo la consejería, el coaching, alguna psicoterapia de inspiración psicoanalítica, etc. Pero para precisar este uso es necesario antes entender que lo que está en el centro del psicoanálisis es la experiencia de la clínica, que el quid del asunto es ese encuentro entre el analista y el analizante ${ }^{5}$. En otras palabras -y para meternos de lleno al tema- el psicoanálisis no es exactamente una teoría del inconsciente, sino sobre todo una teoría de la práctica clínica, lo que sucede es que al analizar los fenómenos que acontecen en dicha práctica la estructura que viene a explicar su orden y que se impone no es otra que la del inconsciente. Porque es la experiencia clínica la que lleva a Freud en un inicio a formular su noción de inconsciente, y no una idea preconcebida del inconsciente lo que hace crear el dispositivo del análisis.

Esto se ve claramente en el inicio de su obra cuando notamos que el primer fenómeno que le sirvió para llegar al descubrimiento del inconsciente fue aquel en donde los síntomas de los pacientes eran susceptibles de la palabra, no importaba si esta venía de la persona en tratamiento o de la interpretación del analista, la palabra tenía un poder, eso era innegable. Todo el trabajo de Freud tuvo como eje poder responder a la pregunta ¿cómo es posible que la palabra pueda operar sobre el síntoma? Así deduce su noción de inconsciente y una serie de mecanismos que desde ahí va aislando poco a poco.

El que entendió mejor este recorrido de Freud fue Jacques Lacan, quien buscó siempre los medios de ordenar ese bosque de conceptos y conjeturas que era la obra del fundador, y que había llevado a muchos a extravíos increíbles ${ }^{6}$. Este último toma la posta en la consigna freudiana pero buscando esta vez darle un rigor formal a las teorías que el fundador había elaborado.

Por ello, una de las principales tesis de Lacan es aquella que responde a la pregunta sobre las condiciones de posibilidad del psicoanálisis, tesis que es ahora muy conocida y que toma la siguiente forma: el psicoanálisis es posible si y solo si, el inconsciente está estructurado como un lenguaje. Es verdad que Freud nunca dijo semejante proposición, pero la idea de Lacan es que la única forma de explicar los efectos de la palabra en los sujetos es a partir de este aforismo que postula que el inconsciente y el lenguaje tienen una estructura homóloga.

5 Analizante es el término que utiliza Lacan para referirse a la persona que está en un análisis, pues para Lacan es éste el que realiza el verdadero trabajo de analizar. La intervención del analista se limita a puntuar el discurso del analizante, a interrogar, en otras palabras, a ser motor de la operación de analizar que realiza ese sujeto. Esto dista mucho de la idea que suele tenerse en cuanto a la forma en que interviene un analista donde éste hace explicaciones "sabias" del pasado o utiliza la fórmula: lo que realmente pasa con usted es...

6 Sin duda la más notable es aquella que pretende hacer del yo el concepto eje del psicoanálisis y que propone una cura por medio de una identificación a un ideal que eventualmente sería la persona del analista. Aún en la actualidad hay muchas personas que consideran que en esto consiste el psicoanálisis, sin embargo Lacan se opuso abiertamente a esta concepción desde un primer momento en un trabajo conocido como El estadio del espejo como formador de la función del yo tal como se nos revela en la experiencia analítica, lo que le valió en buena parte su separación de la International Psychoanalytic Association (IPA). 
Entonces, la respuesta de Lacan a la pregunta de Freud sería la siguiente: si la palabra es capaz de operar sobre el síntoma es solo porque este último es efecto de la estructura de lenguaje que posee el inconsciente. De la misma manera los lapsus, los sueños y una serie de fenómenos inconscientes -que Lacan llamará formaciones del inconsciente- son producto de una dinámica isomorfa a la que se da en el campo del lenguaje. Esto nos permite decir que un estudio de psicoanálisis debe pretender poder verificar la pertinencia de aquella fórmula de Lacan.

Una lectura directa de Freud -y no a través de otros autores- ya permite comprobar los planteamientos de Lacan, pues no es complicado observar que las manifestaciones del inconsciente que el primero explica son efecto de mecanismos que tienen su correlato en el campo del lenguaje. En otras palabras, aquello que Freud llamaba condensación y desplazamiento -mecanismos a través de los cuales entra en acción el inconsciente-, son mecanismos que en el terreno del lenguaje toman el nombre de metáfora y metonimia.

Es fácil ya deducir que para nuestro estudio es necesario hacer un pequeño recorrido en el campo de la lingüística, sobre todo en aquel movimiento en el cual Lacan se apoyó. Nos referimos a la lingüística estructural, pero sobre todo a los trabajos de Ferdinand de Saussure y de Roman Jakobson. Este último amigo cercano de Lacan.

Ahora, si bien es cierto que Lacan toma su noción de estructura de lenguaje de la lingüística, es verdad también que dicha apropiación no es sin antes producir algunas modificaciones a ella, pues lo que le interesa a Lacan es dar cuenta del sujeto del inconsciente y para ello habrá de hacer un refinamiento de la noción prestada. Esta operación tiene toda validez pues no es posible tomar conceptos que intentan dar cuenta de fenómenos que son propios de un campo de estudio para dar cuenta de los fenómenos de otro, se correría el peligro de caer en una simple explicación metafórica, es decir no se estaría demostrando realmente nada, ya que los conceptos que se han tomado prestados han sido construidos a partir de objetos de estudio cualitativamente diferentes.

Una de las transformaciones conceptuales más importantes a tener en cuenta para comprender a Lacan es aquella en donde señala -a diferencia de lo postulado por Saussure- que el significante tiene la primacía sobre el significado y no viceversa. La tesis de Lacan está en contra de que un significante esté unido a un significado unívocamente, por ejemplo, el significante luna unido al significado único satélite natural de la tierra. Él postula que la única manera que un significante encuentre su significado es a través de la articulación con otro significante, es decir cuando digo luna la única forma de saber de qué se trata es cuando aparece articulado con otros significantes, por ejemplo sol, luna, estrellas. Pues si apareciera articulado de la forma luna de miel otro es el efecto de significación.

Darle la primacía al significante es una de las operaciones más importantes de Lacan ya que es a partir de ella que puede crear una teoría del lenguaje que considere dentro de su fenomenología a los lapsus, los sueños, los síntomas e incluso una serie de funciones psíquicas que uno pensaría imposible incluir, como por ejemplo la función del ideal e incluso el falo. Podemos decir entonces que es gracias a 
esta inversión del postulado saussuriano que Lacan puede explicar la estructura de lenguaje que posee el inconsciente.

Todo esto nos permite decir que los primeros años de la enseñanza de Lacan -marco en el que se inscribe el trabajo del Grupo de estudio- no se entienden si no se ve allí un trabajo de dilucidación de la obra de Freud a la luz de lo que le ofrece su teoría del significante.

El alcance de esta teoría significante es muy amplio, permite derivar de ella una serie de postulados que tienen su pertinencia y legitimidad pero cuyas razones no son necesariamente evidentes cuando no se tiene cierto conocimiento de ella. No obstante, cuando uno se ha aproximado lo suficiente a este trabajo de Lacan, puede notarse que es absolutamente necesario detenerse en aquella proposición que quedará sin variación a lo largo de toda su enseñanza y que apunta a que el emisor recibe del receptor su propio mensaje de forma invertida. Dicha proposición es vital para comprender la dirección que toma el analista en una cura y en el uso que hace este de la palabra.

Esa frase vendría a explicar la estructura de la comunicación humana en donde el sentido de un mensaje no es decidido por su emisor. Un ejemplo simple de ello nos lo podría dar aquella situación donde la persona que emite el mensaje sufre un momento de incertidumbre al no saber cómo será tomado por -digamos- su jefe o su pareja; o cuando uno no sabe si lo que ha dicho es algo brillante o una torpeza hasta que alguien sanciona con una sonrisa o un desdén. Siempre hay un tiempo de incertidumbre entre el instante en que uno emite un mensaje y el momento en que este es sancionado.

Sin duda, estos ejemplos quedan cortos para expresar toda la riqueza del enunciado de Lacan, pero como hemos dicho pretendemos solamente hacer una mostración de los puntos fundamentales. Por ello, lo importante sería mencionar que lo que está en juego en esta estructura de la comunicación es algo que él llamará intersubjetividad, esto quiere decir simplemente que en todo diálogo el sujeto siempre se dirige a un tercero que Lacan llama Otro (con mayúsculas), que en toda comunicación hay Otro implicado y que incluso si hablamos solos en una habitación se puede apreciar muy bien cómo es que el discurso del sujeto se dirige siempre a una dirección. Esto es fundamental a lo largo de toda la enseñanza de Lacan.

Este punto que mencionamos se articula perfectamente con lo que venimos señalando que para Lacan la psique humana tiene una estructura intersubjetiva y dicha estructura es homóloga a la estructura del lenguaje una vez que se reconoce la primacía del significante sobre el significado.

Es así que en su primera enseñanza Lacan concluirá dos cosas de todo este tramado intersubjetivo:

1.- Por estructura el lenguaje induce automáticamente a la sugestión, es decir, a que el sujeto se haga permeable a la palabra de ese Otro que decide en su propio mensaje. Es justamente por ello que en su primera enseñanza Lacan se encuentra muy preocupado en buscar una manera de intervenir o de hacer uso de la palabra sin caer en un 
fenómeno de sugestión. A esta vertiente sugestiva Lacan le llamará palabra vacía y consiste en la alienación del sujeto al discurso de un Otro.

2.- Lacan encuentra una manera de hacer uso de la palabra sin caer en el campo de la sugestión, es decir desarrolla un modo de intervención que se centra en la puntuación del discurso del analizante así como en la interrogación. De esta forma se impedían las grandes explicaciones -a veces delirantes- del analista que al entender de Lacan no hacían más que llevar al sujeto a la alienación a un Otro. Esto es muy importante porque implica que la estructura del lenguaje puede funcionar de tal manera que sirva también para revelar la verdad del sujeto. A este uso de la palabra que no aliena al sujeto al Otro, Lacan le llamará vertiente de la palabra plena.

Para Lacan nada muestra mejor la intersubjetividad de la comunicación que el surgimiento de una palabra plena, en dicha situación se puede observar que el analizante necesita que su verdad sea dicha por el analista para encontrarse con ella, pues por sí solo él no puede advertir que ella se encuentra subrepticiamente en su enunciado. Es como si el sujeto necesitara para la comprensión de su verdad el eco del analista, a veces basta simplemente que este último repita la misma frase para toparse con una significación diferente y reveladora.

Antes de concluir debemos añadir que para este trabajo no hemos considerado oportuno desarrollar dos cuestiones fundamentales de la obra de Lacan. La primera tiene que ver con la diferencia que establece entre el yo y el sujeto,diferencia fundamental que sirve para precisar los conceptos de palabra plena y palabra vacía, pero sobre todo para entender por qué el psicoanálisis no consiste en hacer consciente los contenidos inconscientes. Queda pendiente entonces dicha labor.

La segunda se refiere a la cuestión del deseo. De ella solo adelantaremos que sufrió algunas modificaciones a lo largo de su enseñanza, por ejemplo en un primer momento el deseo en Lacan será susceptible de ser nombrado y estará íntimamente ligado con la definición de deseo de Hegel. En cambio, en un segundo momento abandona esta concepción y dirá que el deseo es justamente aquello que no puede ser nombrado por el lenguaje. Es este punto el que marca el inicio de la última enseñanza Lacan y el término de nuestro programa de estudio actual.

\section{REFERENCIAS BIBLIOGRÁFICAS}

Lacan, J. (2008). Escritos 1. Buenos Aires: Editorial Siglo XXI.

Miller, J. (2006). Recorrido de Lacan: ocho conferencias. Buenos Aires: Editorial Manantial.

Saussure, F. (2007). Curso de lingüística general. Buenos Aires: Editorial Losada

Jakobson, R. y Halle, M. (1967). Fundamentos del lenguaje. Madrid: Editorial Ciencia Nueva. 